\title{
Anticancer Drug-induced Thyroid Dysfunction
}

\author{
Saptarshi Bhattacharya, ${ }^{1}$ Alpesh Goyal, ${ }^{2}$ Parjeet Kaur, ${ }^{3}$ Randeep Singh ${ }^{4}$ and Sanjay Kalra ${ }^{5}$ \\ 1. Max Super Speciality Hospital, Patparganj, New Delhi, India; 2. All Indian Institute of Medical Sciences, New Delhi, India; \\ 3. Medanta, The Medicity, Gurugram, India; 4. Narayana Superspeciality Hospital, Gurugram, India; 5. Bharti Hospital, Karnal, India
}

DOI: $h$ ttps://doi.org/10.17925/EE.2020.16.1.32

\begin{abstract}
C ancer immunotherapy and targeted therapy, though less toxic than conventional chemotherapy, can increase the risk of thyroid dysfunction. Immune checkpoint inhibitors render the cancer cells susceptible to immune destruction, but also predispose to autoimmune disorders like primary hypothyroidism as well as central hypothyroidism secondary to hypophysitis. Tyrosine kinase inhibitors act by blocking vascular endothelial growth factor receptors and their downstream targets. Disruption of the vascular supply from the inhibition of endothelial proliferation damages not only cancer cells but also organs with high vascularity like the thyroid. Interferon- $\alpha$, interleukin-2 and thalidomide analogues can cause thyroid dysfunction by immune modulation. Alemtuzumab, a monoclonal antibody directed against the cell surface glycoprotein CD52 causes Graves' disease during immune reconstitution. Metaiodobenzylguanidine, combined with 131-iodine, administered as a radiotherapeutic agent for tumours derived from neural crest cells, can cause primary hypothyroidism. Bexarotene can produce transient central hypothyroidism by altering the feedback effect of thyroid hormone on the pituitary gland. Thyroid dysfunction can be managed in the usual manner without a requirement for dose reduction or discontinuation of the implicated agent. This review aims to highlight the effect of various anticancer agents on thyroid function. Early recognition and appropriate management of thyroid disorders during cancer therapy will help to improve treatment outcomes.
\end{abstract}

\section{Keywords}

Thyroid, hypothyroidism, anticancer drugs, immune checkpoint inhibitors,

tyrosine kinase inhibitors

Disclosures: Saptarshi Bhattacharya, Alpesh Goyal, Parjeet Kaur, Randeep Singh and Sanjay Kalra have no financial or non-financial relationships or activities to declare in relation to this article. Sanjay Kalra is a member of the journal's Editorial Board.

Review Process: Double-blind peer review.

Compliance with Ethics: This article involves a review of literature and does not report on new clinical data, or any studies with human or animal subjects performed by any of the authors.

Authorship: All named authors meet the criteria of the International Committee of Medical Journal Editors for authorship for this manuscript, take responsibility for the integrity of the work as a whole and have given final approval for the version to be published.

Access: This article is freely accessible at touchENDOCRINOLOGY.com ( ) Touch Medical Media 2020

Received: 12 September 2019

Accepted: 8 November 2019

Published Online: 4 February 2020

Citation: European Endocrinology. 2020;16(1):32-9

Corresponding Author: Saptarshi Bhattacharya, Max Super Speciality Hospital, 108A IP Extension,

Patparganj, Delhi, 110092, India. E: saptarshi5@yahoo.com

Support: No funding was received in

the publication of this article.
The armamentarium of anticancer drugs available to an oncologist has grown rapidly over the past few decades. The use of cancer immunotherapy and targeted therapy has become more popular in the last few years. It has also become increasingly clear that various anticancer agents, both conventional and newer ones, may be associated with certain off-target adverse effects involving the endocrine system, especially the thyroid gland. ${ }^{1}$ The site of action of commonly used cancer immunotherapy agents is depicted in Figure 1. This article is aimed at describing thyroid dysfunction associated with various anticancer agents. These have been briefly summarised in Table 1. It is important to identify and appropriately treat thyroid dysfunction in such patients. This will not only improve their overall quality of life, but also ensure optimal treatment outcome.

\section{Literature search}

A MEDLINE search was conducted for articles published before 30 April 2019. Articles published in English were considered. The search terms were words related to thyroid disorders, such as 'thyroid', 'hypothyroidism', 'thyrotoxicosis', 'hyperthyroidism' 'Graves' disease' 'central hypothyroidism', and 'thyroiditis' in association with 'anticancer drugs', 'immune checkpoint inhibitors', 'tyrosine kinase inhibitors', 'interferon- $\alpha$,'interleukin-2,' 'alemtuzumab', 'thalidomide,',lenalidomide','pomalidomide' 'radioiodine-based cancer therapies' and 'bexarotene'. The names of specific drugs, like ipilimumab, nivolumab and pembrolizumab amongst immune checkpoint inhibitors; and sunitinib, sorafenib, axitinib, pazopanib, vandetanib, motesanib, imatinib, cabozantinib, nilotinib, dasatinib, erlotinib, gefitinib, lapatinib, nintedanib, regorafenib and tivozanib amongst tyrosine kinase inhibitors, were also included in the search. The abstracts were evaluated for relevance, and the full text of all appropriate articles was retrieved. Reference lists of selected articles were also searched. Articles describing usage of anticancer agents for the treatment of thyroid cancer were excluded.

\section{Immune checkpoint inhibitors}

A better understanding of the complexities of the human immune system and its regulation paved the way for a novel concept in the field of oncology termed 'cancer immunotherapy'. The basic principle of cancer immunotherapy is utilisation of the body's own immune system to target cancer cells. Immune checkpoint molecules are regulators of the immune system which provide self-tolerance and prevent the immune system from destroying its own cells (Figure 2). These include cytotoxic T-lymphocyte associated protein 4 (CTLA-4) and programmed cell death protein 1 (PD-1; a cell surface receptor) and its ligand (PD-L1). CTLA-4 is constitutionally expressed on regulatory $T$ cells, gets up-regulated on T-cell activation, and works toward inhibiting a second (co-stimulatory) signal for T-cell activation. PD-1 is present on T cells, B cells and natural killer (NK) cells, and binds to PD-L1 expressed by tumour cells. The interaction between PD-1 and PD-L1 inhibits the destruction of tumour cells by the immune system; hence, PD-L1 is overexpressed by the tumour cells to their advantage., ${ }^{2,3}$ 


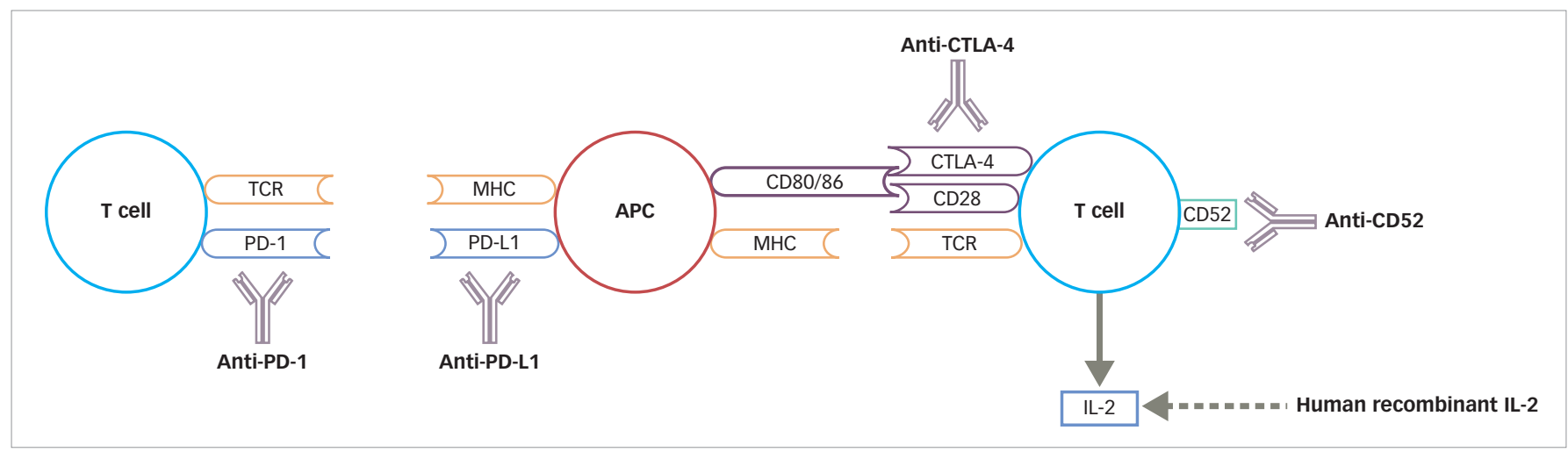

$A P C=$ antigen presenting cell; $C D=$ cluster of differentiation; $C T L A-4=$ cytotoxic $T$ lymphocyte associated protein-4; IL-2 = interleukin-2; $M H C=$ major histocompatibility complex; $P D-1=$ programmed cell death protein-1; $P D-L 1=$ programmed death-ligand $1 ; T C R=$ T-cell receptor

Table 1: Anticancer drugs causing thyroid dysfunction

\begin{tabular}{|c|c|}
\hline \multirow{2}{*}{$\begin{array}{l}\text { Immune checkpoint } \\
\text { inhibitors }\end{array}$} & Hypophysitis (ipilimumab, nivolumab) \\
\hline & $\begin{array}{l}\text { Primary thyroid dysfunction (ipilimumab, } \\
\text { nivolumab, pembrolizumab) }\end{array}$ \\
\hline \multirow[t]{2}{*}{ Tyrosine kinase inhibitors } & $\begin{array}{l}\text { Hypothyroidism (sunitinib, sorafenib, axitinib, } \\
\text { pazopanib, vandetanib, motesanib) }\end{array}$ \\
\hline & $\begin{array}{l}\text { Increased levothyroxine requirement in } \\
\text { thyrodectomised patients (imatinib, sorafenib, } \\
\text { motesanib) }\end{array}$ \\
\hline Interferon- $\alpha$ & Hypothyroidism, destructive thyroiditis \\
\hline Interleukin-2 & Hypothyroidism \\
\hline Alemtuzumab & Graves' disease \\
\hline Thalidomide analogues & $\begin{array}{l}\text { Hypothyroidism, ischaemic thyroiditis } \\
\text { (thalidomide, lenalidomide) }\end{array}$ \\
\hline $\begin{array}{l}\text { Radioiodine-based cancer } \\
\text { therapy }\end{array}$ & Hypothyroidism, radiation thyroiditis \\
\hline Bexarotene & Central hypothyroidism \\
\hline Conventional agents & $\begin{array}{l}\text { Alteration in thyroid binding proteins (not clinically } \\
\text { relevant) (mitotane, 5-fluorouracil, oestrogens, } \\
\text { tamoxifen, podophyllin, L-asparaginase) }\end{array}$ \\
\hline
\end{tabular}

\section{Indications and adverse events}

Immune checkpoint inhibitors are agents that inhibit these immune checkpoint molecules, causing an immune attack on the tumour cells. The US Food and Drug Administration (FDA)-approved immune checkpoint inhibitors include anti-CTLA-4 monoclonal antibody (ipilimumab), anti-PD-1 monoclonal antibody (nivolumab, pembrolizumab), and anti-PD-L1 monoclonal antibody (atezolizumab, avelumab, and durvalumab). While initially approved for the treatment of unresectable or metastatic melanoma, these agents have been found to be effective in a wide variety of tumours, such as small-cell lung cancer, non-small-cell lung cancer (NSCLC), Hodgkin's lymphoma, renal cell cancer (RCC), prostate cancer, bladder cancer, oesophageal cancer and breast cancer. ${ }^{4}$ The enhanced immune activation seen with these agents can lead to a variety of immune-related adverse events. These may involve a number of organ systems - skin (rash, pruritus), gastrointestinal tract and liver (colitis, autoimmune hepatitis), and the endocrine system (hypophysitis and thyroid dysfunction). In terms of endocrine dysfunction, hypophysitis has been reported more often with CTLA-4 inhibitors, while thyroid dysfunction has been reported with both CTLA-4 and PD-1/PD-L1 inhibitors. ${ }^{4}$

\section{Hypophysitis and central hypothyroidism}

Hypophysitis related to CTLA-4 inhibitor therapy has been reported at an incidence of $0.4-17.0 \%$ in literature. ${ }^{5-7}$ Similar to autoimmune lymphocytic hypophysitis, there is predilection for involvement of thyrotropes (central hypothyroidism) and corticotrophs (central hypoadrenalism). However, unlike lymphocytic hypophysitis, CTLA-4 inhibitor-related hypophysitis is more common in males. A possible reason could be the higher proportion of male participants in studies reporting hypophysitis with CTLA-4-inhibitor therapy. In a retrospective study involving 154 adult subjects with melanoma treated with ipilimumab at a tertiary care centre in USA, hypophysitis was reported at a prevalence of $11 \%(17 / 154) .{ }^{6}$ The prevalence was significantly higher in males compared with females (15.6\% versus $3.6 \%$ ), and subjects with hypophysitis were significantly older compared to the remaining cohort (mean age 68.2 versus 59.9 years). The diagnosis of hypophysitis was made after a median duration of 8.4 weeks following the initiation of ipilimumab. Central hypothyroidism was reported in all, while central hypoadrenalism was seen in $42 \%(7 / 17)$ subjects with hypophysitis. Interestingly, the median survival in subjects who developed hypophysitis was significantly higher than those who did not (19.4 versus 8.8 months). In another study by Ryder et al. ( $n=254)$, the overall incidence of hypophysitis following ipilimumab therapy was $8 \%$, while in the subjects receiving combination immune checkpoint-inhibitor therapy (ipilimumab and nivolumab), the incidence increased to $9 \%$.

\section{Primary thyroid dysfunction}

Primary thyroid dysfunction following immune checkpoint-inhibitor therapy has been described in the form of subclinical or overt hypothyroidism, transient thyrotoxicosis and painless thyroiditis. ${ }^{4-7}$ Rare cases of Graves' disease and euthyroid orbitopathy have also been described. ${ }^{8-10}$ The incidence of thyroid dysfunction following immune checkpoint-inhibitor therapy has been variably reported at $1-22 \%$ in the literature. ${ }^{47,8-11}$ The incidence is much higher in patients receiving a combination therapy (CTLA-4 inhibitor and PD-1 inhibitor). In the study by Ryder et al., the overall incidence of hypothyroidism/thyroiditis following ipilimumab was $6 \%$, while it increased to $22 \%$ in those receiving a combination of ipilimumab and nivolumab.?

In the KEYNOTE-001 study, 51 subjects with advanced NSCLC treated with PD-1 inhibitor pembrolizumab were studied for thyroid dysfunction. Of the 48 subjects with euthyroidism at baseline, 10 (21\%) developed hypothyroidism (requiring replacement) at a median duration of 6 weeks. Hypothyroidism was preceded by a phase of transient thyrotoxicosis in 6/10 (60\%) subjects. Anti-thyroid antibodies were more frequent in 
Figure 2: Mechanism of action of immune checkpoint inhibitors

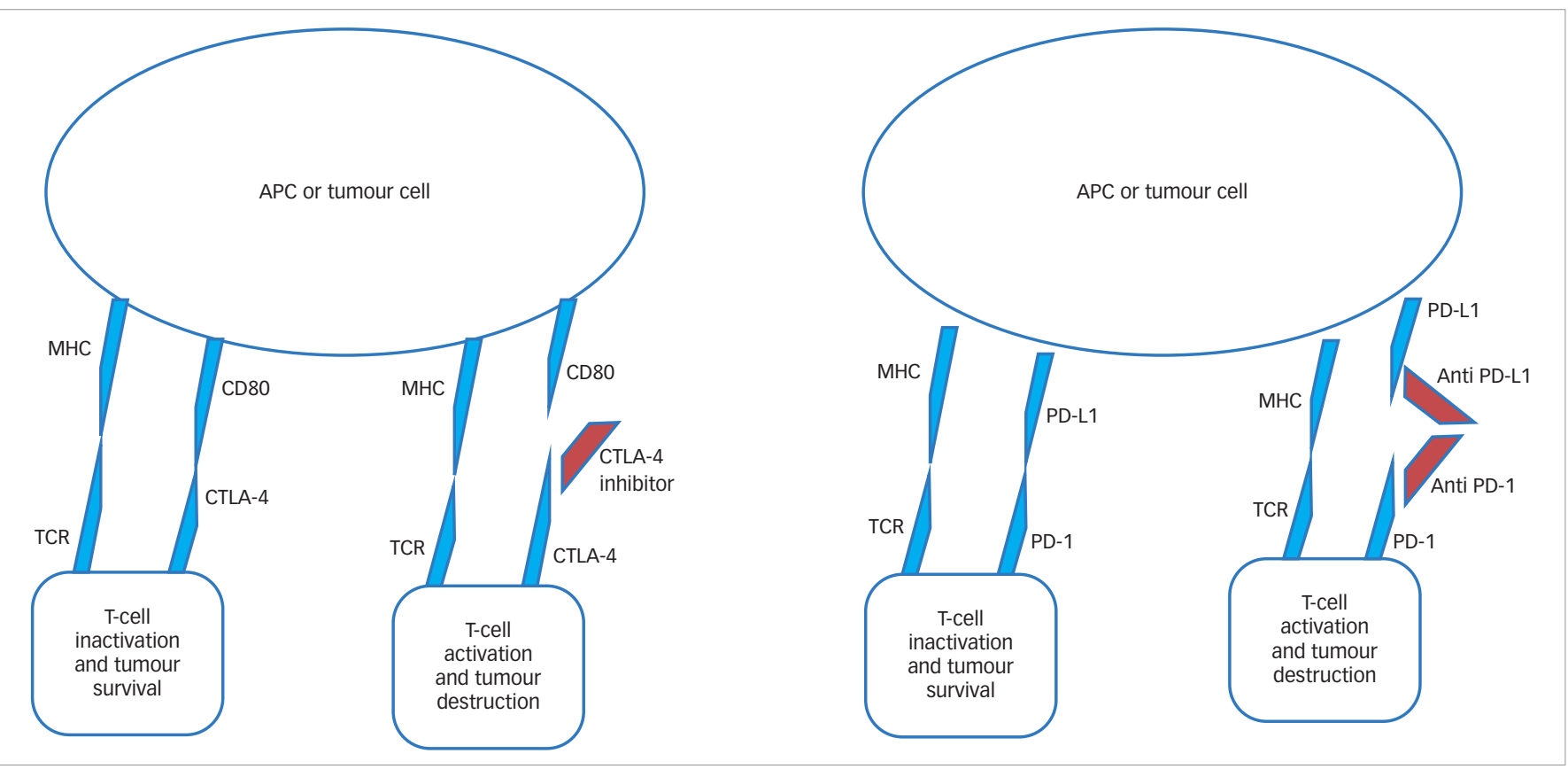

$A P C=$ antigen presenting cell; CTLA-4 = cytotoxic $T$ lymphocyte associated protein-4; $M H C=$ major histocompatibility complex; $P D-1=$ programmed cell death protein-1; $P D-L 1=$ programmed death-ligand 1; TCR $=$ T-cell receptor .

the subset of subjects who developed thyroid dysfunction (8/10, $80 \%$, compared to those who did not $(3 / 38,8 \%) .{ }^{11}$ Similar to the ipilimumab hypophysitis study, subjects developing thyroid dysfunction had overall better survival (hazard ratio, 0.29; 95\% confidence interval 0.09-0.94; $\mathrm{p}=0.04$ ). The authors concluded that primary thyroid dysfunction following pembrolizumab therapy is fairly common, occurs early, is associated with transient thyrotoxicosis and anti-thyroid antibodies in most cases, and possibly portends a favourable outcome.

The association between immune checkpoint inhibitor-related endocrine dysfunction and better overall survival seen in various studies might indicate higher immune activation and better tumour-cell destruction by the immune system in subjects developing this adverse effect. This interesting observation needs further validation with well-designed, long-term follow-up studies.

\section{Management}

The mainstay of management of thyroid dysfunction following immune checkpoint inhibitor therapy involves appropriate thyroid hormone replacement. 12,13 In patients with combined adrenal and thyroid dysfunction due to immune checkpoint inhibitor-related hypophysitis, thyroid hormone replacement should begin 3-5 days after initiation of glucocorticoid replacement in order to avoid an acute adrenal crisis. Endocrine dysfunction following immune checkpoint inhibitor-related hypophysitis is generally irreversible, and high-dose glucocorticoids should only be considered in patients with significant mass effects or severe hyponatraemia. ${ }^{14,15}$ In terms of primary thyroid dysfunction, subclinical hypothyroidism (with normal free thyroxine [FT4] and thyroid stimulating hormone $[\mathrm{TSH}]<10 \mathrm{mIU} / \mathrm{L}$ ) could be managed with careful observation and close follow-up. ${ }^{4}$ Thyrotoxicosis is typically transient (ultimately giving way to primary hypothyroidism), and may be treated with beta blockers for a brief duration. A radioiodine scan may help to differentiate thyrotoxicosis related to thyroiditis from hyperthyroidism related to Graves' disease. However, one should be cognisant of the fact that such patients frequently undergo iodinated contrast-based imaging for their primary disease. This may interfere with the uptake of radioiodine by saturating the thyroid gland iodine pool.

\section{Tyrosine kinase inhibitors}

Tyrosine kinase inhibitors (TKIS) are one of the most potent classes of targeted therapy drugs, used against many different cancer types. They inhibit the enzyme tyrosine kinase, which is involved in the transfer of phosphate from adenosine triphosphate to tyrosine residues in the catalytic domain of growth factor receptors. By this mechanism, TKIs inhibit vascular endothelial growth factor receptors (VEGFRS) and their downstream targets, and suppress endothelial proliferation. The prevention of vascular growth in the tumour causes disruption to the supply of nutrients and oxygen and kills the tumour cells. ${ }^{16}$

\section{Indications and thyroid dysfunction associated with tyrosine kinase inhibitors}

Currently, the FDA has approved more than 20 different TKIs for clinical use. ${ }^{17}$ In comparison to traditional cytotoxic antineoplastic agents, TKIs have high selectivity, high efficacy, a low number of side effects and have superiority in the treatment of chronic myeloid leukaemia, NSCLC and RCC. They are also active against medullary thyroid cancer and differentiated thyroid cancer refractory to iodine-131 (I-131), gastrointestinal stromal tumour (GIST), pancreatic neuroendocrine tumours and hepatocellular carcinoma. ${ }^{16}$ Thyroid dysfunction is recognised as an important but manageable side effect of TKIs. Although all TKIs act through the same mechanism, they differ in their spectrum of targeted kinases, thereby resulting in varying rates of thyroid dysfunction. TKIs can induce de novo hypothyroidism which can be preceded by a phase of transient thyrotoxicosis in $20-40 \%$ cases. $^{18}$ The TKIs which are known to induce new-onset hypothyroidism in a significant proportion of patients include sunitinib, sorafenib, axitinib, pazopanib, vandetanib and motesanib. ${ }^{19}$ The other variety of thyroid dysfunction induced by TKI is increased levothyroxine (LT4) requirements in patients who have been on stable doses of thyroid hormone replacement following thyroidectomy for other reasons. ${ }^{20}$ 


\section{Sunitinib-induced thyroid dysfunction}

The TKI most frequently associated with development of new onset hypothyroidism is sunitinib. ${ }^{21-6}$ It is approved for the treatment of RCC and GISTs resistant to therapy with imatinib. Hypothyroidism occurs in $14-70 \%$ of recipients in different studies. ${ }^{21-3} \mathrm{~A}$ meta-analysis of seven randomised trials which included 2,787 subjects revealed a risk ratio for all and high-grade hypothyroidism of 13.95 and 4.78 , respectively. ${ }^{24}$ The risk of developing hypothyroidism increases with time and with the number of cycles of therapy. ${ }^{25}$ The time for development of thyroid dysfunction in the two largest series with long follow-up was found to vary from as early as 4 weeks to as late as 92 weeks. ${ }^{25,26}$

\section{Thyroid dysfunction induced by other tyrosine kinase inhibitors}

Sorafenib is used for the treatment of patients with metastatic RCC, advanced hepatocellular carcinoma and radioactive iodine-resistant advanced thyroid cancer. The incidence of thyroid dysfunction with sorafenib is much less when compared to sunitinib, ranging between 6.3-27.0\%. ${ }^{27-9}$ The median time to develop hypothyroidism was 20 months, but an increase in TSH could appear as early as 6 weeks after initiation of treatment.27,29 In the phase III AXIS trial, axitinib, used for treatment of RCC, caused hypothyroidism more commonly compared to sorafenib (21\% versus 7\%). ${ }^{30}$ Pazopanib, a TKI approved for the treatment of RCC and soft tissue sarcoma, has reported rates of hypothyroidism of around $12 \%$ or less. ${ }^{31}$ Other TKIs linked with hypothyroidism include cabozantinib, nilotinib, dasatinib, erlotinib, gefitinib, lapatinib, nintedanib, regorafenib and tivozanib. ${ }^{17}$

\section{Mechanism of tyrosine kinase inhibitor-induced hypothyroidism}

The pathophysiology behind the development of hypothyroidism is presumed to be vascular, resulting from its anti-angiogenic effect. The thyroid gland is a highly vascular organ and its blood flow is mainly dependent on VEGFR signalling. Broad spectrum TKIs like sunitinib, which not only inhibits VEGFR2 and VEGFR3, but also VEGFR1 and the platelet-derived growth factor receptor (PDGFR), impairs vascularisation of the thyroid and induces thyroid ischaemia. ${ }^{32}$ However, PDGFR signalling does not play a role in thyroid angiogenesis in physiological conditions, but becomes active in ischaemia. The compensatory mechanism to restore vascularity might get impaired when it is inhibited. ${ }^{33}$ The differential effect of various TKIs in inducing thyroid dysfunction can be attributed to their selectivity to block diverse vascular growth factor signalling pathways. A rapid reduction in thyroid vascular flow can result in ischaemic thyroiditis and produce the preceding transient thyrotoxic phase. ${ }^{34}$ Interestingly, hypothyroidism resulting from TKIs has been associated with longer survival for unclear reasons. ${ }^{35}$

\section{Tyrosine kinase inhibitors in thyroidectomised patients}

Another type of thyroid dysfunction occurs in thyroidectomised patients who have a worsening of stable hypothyroidism and increased LT4 requirement after initiating TKI therapy. Imatinib, currently used in the treatment of chronic myeloid leukaemia, GISTs and other haematological cancers, is most commonly associated with this phenomenon. Imatinib does not induce hypothyroidism in those with an intact thyroid gland. ${ }^{20}$ Sorafenib and motesanib have also been reported to cause similar elevation in TSH in patients with pre-existing hypothyroidism. ${ }^{36,37}$ The possible mechanisms could be stimulation of type 3 deiodinase activity leading to increased peripheral inactivation of thyroid hormones and a dose-dependent inhibition of thyroid hormone transport protein, monocarboxylate transporter. ${ }^{35,38}$ Additionally, reduced pituitary type 2 deiodinase activity can cause intracellular depletion of triiodothyronine (T3) in the thyrotrophs and an inappropriate elevation of TSH for the concomitant serum free T3 and FT4 levels. ${ }^{32}$

\section{Screening and management of tyrosine kinase inhibitor-induced thyroid dysfunction}

Drui et al. recommend screening by measurement of TSH at the initiation of TKI treatment and then monthly (or on the first day of a new cycle in cases of interrupted treatment) for the first 6 months. Thereafter, TSH estimation should be done every 2-3 months or in the event of clinical signs of thyroid disorder. In individuals with pre-existing hypothyroidism, TSH should be monitored monthly for the first 3 months, followed by monitoring at 3-monthly intervals throughout the therapy period. LT4 should be initiated if TSH is $>10 \mathrm{mIU} / \mathrm{L}$ or if TSH is between 5-10 mIU/L on two assays, along with clinical symptoms, presence of anti-thyroid antibodies or ultrasound evidence of autoimmune thyroiditis. After the end of TKI treatment, a trial of withdrawal of LT4 should be considered with appropriate monitoring. ${ }^{39}$

\section{Other immunomodulators}

\section{Interferon- $\alpha$}

Interferon- $\alpha$ (IFN- $\alpha$ ) is a cytokine approved for treatment of hepatitis $C$ virus (HCV) and several kinds of malignancies like melanoma, RCC, Kaposi's sarcoma. It is also used for the treatment of hairy cell leukaemia and follicular lymphoma. In recent years, it has largely been replaced as an anticancer agent by better alternatives. It exerts a direct antitumour effect and also indirectly causes the immune-mediated destruction of tumour cells by inducing the expression of major histocompatibility complex-1 (MHC-1), tumour-specific antigen and adhesion molecules on the cell surface. ${ }^{40}$

The mechanism of IFN- $\alpha$-induced thyroid dysfunction (IITD) is not fully understood. The expression of MHC-1 antigens on the cell surface results in the activation of cytotoxic T cells, which in turn causes cellular destruction. ${ }^{41}$ The presence of pre-existing intrathyroidal lymphocytes thereby increases the susceptibility for the development of IITD. This also explains the finding of a higher likelihood of the development of thyroid dysfunction in individuals with anti-thyroid antibodies. ${ }^{42,43}$ Mandac et al. classified IITD in patients with HCV into two groups: autoimmune and non-autoimmune. ${ }^{44}$ Obołończyk et al. suggested the addition of a new term, 'undifferentiated IITD', in view of the variable course of the disease. ${ }^{45}$ The full spectrum of IITD described in patients with HCV may be seen in those receiving IFN- $\alpha$ therapy for malignant conditions. ${ }^{46}$

Clinical thyroid disease is found in $15-20 \%$ of patients with HCV receiving IFN- $\alpha$, and up to $40 \%$ of those become thyroid-antibody positive. ${ }^{45,47}$ Autoimmune hypothyroidism is the most common clinical presentation, occurring in $20 \%$ of cases, followed by destructive thyroiditis (2-3\%). Graves' disease is found rarely. ${ }^{48}$ Notably, HCV infection itself can induce thyroid dysfunction. IFN- $\alpha$ treatment for malignancy carries a lesser chance of the development of thyroid dysfunction compared with patients with $\mathrm{HCV}^{44}$ Thyroid disorders occur in $2.4-31.0 \%$ of patients receiving IFN- $\alpha$ therapy for solid tumours. ${ }^{46}$ It is recommended to screen for thyroid dysfunction with TSH and antithyroid antibodies prior to starting IFN- $\alpha$. Follow-up TSH should be done every 2 months in those with positive antithyroid antibodies and every 6 months in those with negative antibody status. ${ }^{1}$

\section{Interleukin-2 (aldesleukin)}

Interleukin-2 (IL-2) is another cytokine-based therapy used for the treatment of metastatic melanoma and RCC. Its use has declined in recent 
years due to the increased availability of better-tolerated alternatives. IL-2 destroys tumour cells by activating NK cells and antigen-specific T cells. ${ }^{49}$

In a large cohort of 281 patients treated with IL-2 alone, hypothyroidism was reported in $35 \%$ of patients, although only $9 \%$ of patients required LT4. Longer duration of therapy correlated with a higher risk of development of hypothyroidism. Thyrotoxicosis occurred in $7 \%$ of patients receiving high-dose IL-2. The overall incidence of thyroid dysfunction did not differ in the high- and low-dose IL-2 arms. ${ }^{50}$ In data from PROCLAIM ${ }^{\mathrm{sm}}$, a registry of patients receiving high-dose IL-2, $70 \%$ of patients developed primarily vitiligo (in cases of melanoma only) and/or thyroid dysfunction (with a greater incidence in patients with RCC compared with patients with melanoma). The development of these immune-related adverse events correlated with improved tumour control and overall survival. ${ }^{51}$ Hypothyroidism usually ensues by 4-17 weeks after starting IL-2 and may be reversible on discontinuation of treatment. . $253^{2}$ The frequency of thyroid dysfunction is $10-60 \%$ in various reports, but in many of these studies patients received IL-2 in combination with IFN- $\alpha$, lymphokine-activated killer cells, or vaccine. ${ }^{46}$

IL-2 stimulates autoreactive lymphocytes and induces thyroid autoimmunity. It also increases IL-1, tumour necrosis factor-alpha (TNF- $\alpha$ ), and IFN- $\gamma$. These cytokines induce the presentation of human leukocyte antigen class-II (HLA-II) and associated autoantigens on thyrocytes, and causes its autoimmune destruction. ${ }^{54,55}$ High levels of thyroid antibodies prior to treatment amplified the risk of IL-2-induced hypothyroidism. ${ }^{53} \mathrm{TSH}$ should be measured before initiating treatment with $\mathrm{IL}-2$ and then once every $2-3$ months during therapy. ${ }^{1}$

\section{Alemtuzumab}

Alemtuzumab is a recombinant humanised monoclonal antibody that is directed against the cell surface glycoprotein, CD52, present on lymphocytes. It causes profound lymphopaenia by causing complement-mediated lysis of these cells. The change in immune repertoire that occurs during subsequent lymphocyte reconstitution accounts for its therapeutic effect. ${ }^{56}$ It is administered for the treatment of $\mathrm{T}$ cell prolymphocytic leukaemia and chronic lymphocytic leukaemia (CLL). Alemtuzumab is also approved for the treatment of active relapsing-remitting multiple sclerosis (MS). It is used as an immunosuppressive agent following solid organ and stem cell transplant and in graft versus host disease.

Thyroid dysfunction commonly occurs after therapy with alemtuzumab for MS, but has not been reported after treatment of malignant conditions. ${ }^{57-9}$ In a recently published study, thyroid dysfunction occurred in $41 \%$ of 248 patients with MS treated with alemtuzumab. Graves' disease accounted for $72 \%$ of those patients who developed thyroid dysfunction, with a median onset of 17 months following the last alemtuzumab dose, and the majority (89\%) within 3 years. ${ }^{57}$ In another large series of 334 patients with MS, thyroid dysfunction was reported in $34 \%$ of patients receiving alemtuzumab compared with $6.5 \%$ receiving IFN $3-1$ a. Graves' disease was reported in $22 \%$, hypothyroidism in $7 \%$, and subacute thyroiditis in $4 \%$. Thyroid-binding inhibitory immunoglobulin was positive in $74 \%$ of patients with overt hypothyroidism..$^{58}$ Patients receiving alemtuzumab for T-cell prolymphocytic leukaemia and chronic lymphocytic leukaemia did

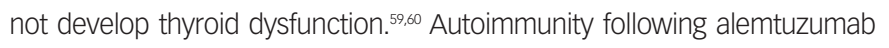
therapy has been attributed to a breakdown in self-tolerance during immune reconstitution and is mediated by humoural mechanisms arising from homeostatic T-cell proliferation. ${ }^{61}$ The absence of thyroid dysfunction in neoplastic conditions in comparison to MS is presumed to be due to the simultaneous use of other immunosuppressive agents in patients with cancer, or to the tendency for underlying autoimmunity in patients with MS. ${ }^{1}$

\section{Thalidomide analogues}

Thalidomide and its analogues lenalidomide and pomalidomide are used for the treatment of multiple myeloma, myelodysplastic syndrome and mantle cell lymphoma. The anticancer effects are mediated by antiangiogenic, antiproliferative and immunomodulatory activity. ${ }^{62}$ The incidence of subclinical hypothyroidism is $20 \%$ and overt hypothyroidism is 7\% during the first 6 months of thalidomide therapy. ${ }^{63}$ In a retrospective series of 170 patients receiving lenalidomide, hypothyroidism was reported in six, and thyrotoxicosis in four. ${ }^{64}$ In another series, lenalidomide caused hypothyroidism in $25.8 \%$ of cases after a median duration of 5.2 months in patients with diffuse large B-cell lymphoma.65 Two case reports of pomalidomide-induced hypothyroidism have been described in the literature. ${ }^{6,67}$ Slean and Silkiss reported a case of lenalidomide-induced eyelid retraction in a 76-year-old woman who was euthyroid but had elevated thyroid antibodies. ${ }^{68}$

One of the probable mechanisms behind the development of hypothyroidism is the induction of ischaemic thyroiditis through the antiangiogenic effect of thalidomide. The deregulation of cytokines or direct effects on T-lymphocytes have also been hypothesised to trigger an autoimmune response to the thyroid. ${ }^{33}$ Elevated anti-thyroid peroxidase antibodies and increased TNF- $\alpha$ levels have been demonstrated in these patients, further corroborating the possibility of immune-mediated pathogenesis.65,69 Additionally, lenalidomide might cause increased T-cell proliferation and activation by stimulating tyrosine phosphorylation of T-cell costimulatory molecules (e.g., CD28). This may inhibit regulatory T cells and might block immune checkpoints like CTLA-4. ${ }^{70,71}$ Measurement of TSH is recommended before initiation of treatment with these agents, and every 2-3 months thereafter for the duration of therapy.72

\section{Radioiodine-based cancer therapy}

Metaiodobenzylguanidine (MIBG) is a norepinephrine analogue. Combined with $\mathrm{I}-131$, it is used as a radiotherapeutic agent to treat tumours derived from neural crest cells. Active transport by uptake-1 system is the dominant mechanism of uptake in these cells, while passive diffusion plays a minor role. ${ }^{73}$

\section{Indications and adverse effects}

I-131 MIBG therapy has been used for a variety of tumours including inoperable pheochromocytoma or paraganglioma, stage III or IV neuroblastoma, inoperable carcinoid tumours and metastatic or recurrent medullary thyroid carcinoma. ${ }^{74}$ Adequate uptake and retention of MIBG during a pre-therapy scan is a prerequisite before the administration of a therapeutic dose of I-131 MIBG. The adverse effects associated with the therapeutic use of I-131 MIBG include transient hypertension, bone marrow suppression and thyroid dysfunction. ${ }^{73}$ During its administration, free radioiodide formed due to chemical instability and biological degradation in the liver may result in toxicity to the thyroid gland.

\section{Spectrum of thyroid dysfunction}

Thyroid dysfunction following I-131 MIBG therapy has been reported in the form of hypothyroidism, radiation thyroiditis, thyroid nodule and thyroid carcinoma. ${ }^{75,76}$ Due to higher radio-sensitivity, the concern remains greater in children receiving this therapy, most commonly for neuroblastoma. Traditionally, when using Iodine-123 or I-131 MIBG for diagnostic or therapeutic purposes, thyroid protection is rendered using a saturated solution of potassium iodide or Lugol's iodine. ${ }^{77}$ Despite the use of thyroid protection, the incidence of thyroid dysfunction following MIBG therapy is quite high, and varies from $52-86 \%$ across studies. ${ }^{77-9}$ 
Table 2: Recommendations for the screening and management of thyroid disorders during anticancer therapy

\begin{tabular}{|c|c|c|}
\hline Drug & Screening & Management \\
\hline \multirow[t]{4}{*}{ Immune checkpoint inhibitors ${ }^{12,13}$} & \multirow[t]{4}{*}{$\begin{array}{l}\text { TSH and FT4 before initiation, should be } \\
\text { repeated before each cycle }\end{array}$} & $\begin{array}{l}\text { Primary hypothyroidism: start standard LT4 therapy: initial full dose }(1.6 \mathrm{mcg} / \mathrm{kg}) \text { in } \\
\text { young and healthy; reduced dose in elderly or patients with cardiovascular disease }\end{array}$ \\
\hline & & Thyroiditis: usually self-limited, beta blockers may be given for a short duration \\
\hline & & Graves' disease: standard therapy \\
\hline & & $\begin{array}{l}\text { Central hypothyroidism due to hypophysitis: start LT4 at } 1 \mathrm{mcg} / \mathrm{kg} \text {, adjust dose by } \\
\text { monitoring FT4 every } 6-8 \text { weeks, rule out or treat associated hypocortisolism } \\
\text { before initiation }\end{array}$ \\
\hline \multirow[t]{4}{*}{ Tyrosine kinase inhibitors ${ }^{37}$} & \multirow{4}{*}{$\begin{array}{l}\text { Euthyroid patients } \\
\text { TSH at initiation and then monthly } \\
\text { (or on first day of new cycle) for first } \\
6 \text { months. TSH every 2-3 months } \\
\text { thereafter or on symptoms } \\
\text { Prior hypothyroidism } \\
\text { TSH monthly for first } 3 \text { months, followed by } \\
\text { 3-monthly throughout the therapy period }\end{array}$} & $\begin{array}{l}\text { Primary hypothyroidism: treat if TSH }>10 \mathrm{mIU} / \mathrm{L} \text { or TSH } 5-10 \mathrm{mIU} / \mathrm{L} \text { on two } \\
\text { assays, with clinical symptoms, positive anti-TPO antibodies or ultrasound signs of } \\
\text { autoimmune thyroiditis } \\
\text { Replacement dose between } 1.0-1.6 \mathrm{mcg} / \mathrm{kg}\end{array}$ \\
\hline & & Thyroiditis: usually self-limited, beta blockers may be given for a short duration \\
\hline & & Graves' disease: standard therapy \\
\hline & & Prior hypothyroidism: increased levothyroxine requirement as adjudged by TSH value \\
\hline I-131 MIBG therapy ${ }^{79}$ & $\begin{array}{l}\text { TSH and FT4 at baseline and at every } \\
3-6 \text { months }\end{array}$ & $\begin{array}{l}\text { Primary hypothyroidism: LT4 therapy if TSH level >10 mIU/L. Some authorities } \\
\text { recommend treatment even with TSH } 5-10 \mathrm{mIU} / \mathrm{L} \text {, because of theoretical risk of } \\
\text { malignancy due to radiation }\end{array}$ \\
\hline Bexarotene ${ }^{93-5}$ & TSH and FT4 at initiation of therapy & $\begin{array}{l}\text { Central hypothyroidism: start LT4 at 25-50 } \mu \text { g along with bexarotene. FT4 levels every } \\
\text { 1-2 weeks for first } 4 \text { weeks; dose adjusted to maintain it at upper third of normal. } \\
\text { Monthly FT4 once levels stable. Treatment discontinued on stopping bexarotene. } \\
\text { Prior hypothyroidism: increased LT4 requirement, and can increase 2-3 times; should } \\
\text { be adjusted according to FT4 levels }\end{array}$ \\
\hline
\end{tabular}

FT4 = free thyroxine; I-131 MIBG = iodine-131 metaiodobenzylguanidine; LT4 = levothyroxine; TPO = thyroid peroxidase; TSH = thyroid-stimulating hormone.

\section{Incidence of thyroid dysfunction}

In a study by van Santen et al., TSH elevation (>4.5 mIU/L) was reported in 22/42 (52\%) subjects with neuroblastoma with a mean follow-up duration of 1.4 years following MIBG therapy.7 In another study by the same group, long-term thyroid outcomes among 25 survivors of neuroblastoma were reported. After a median follow-up of 6 years, 14/25 (56\%) subjects had persistent TSH elevation, while 6/25 (24\%) developed thyroid nodules or cysts..$^{78}$ In another study by Picco et al., at a follow-up of 6-12 months following MIBG therapy, TSH elevation was evident in $12 / 14$ (86\%) survivors of neuroblastoma. Of these, eight (67\%) had overt hypothyroidism, while four (33\%) had compensated hypothyroidism. ${ }^{79}$ In a study comparing two thyroid protection strategies, a combination of potassium iodide, thyroxine and methimazole (cocktail protection) was compared with potassium iodide (standard protection) in children with neuroblastoma receiving therapeutic I-131 MIBG. The study evaluated 23 children who were given the cocktail protection (beginning 1 day before diagnostic I-131 MIBG and continued until 4 weeks after therapeutic I-131 MIBG), and were followed up for a mean duration of 19 months. The control group was historical cohort of children with neuroblastoma $(n=42)$ who received standard thyroid protection. Thyroid function was normal in $86 \%$ survivors in group A (cocktail protection) compared to $44 \%$ in group B (standard protection). The authors thus concluded that a combined protective strategy may be more effective against radiation damage in patients receiving MIBG therapy for neuroblastoma. ${ }^{80}$ The long-term efficacy of this strategy, however, remains to be seen.

\section{Screening and management}

Although a clear recommendation is lacking, it is advisable to obtain a thyroid function at baseline and at 3-6 monthly intervals in patients receiving therapeutic I-131 MIBG. LT4 supplementation is recommended in those with low T4 levels or TSH level >10 mIU/L. However, considering the theoretical concern of increased neoplasm risk with chronically elevated TSH levels, some authors recommend treating even mild subclinical hypothyroidism (TSH $<10 \mathrm{mIU} / \mathrm{L}$ ) in the setting of previous radiation exposure. ${ }^{81}$ Since thyroid radiation is a known risk factor for malignancy, and increased incidence of thyroid nodule has been reported in studies, such patients should be followed indefinitely for the same.76,78

\section{Bexarotene}

Topical and systemic preparation of bexarotene, a third-generation retinoid analogue, is approved for the treatment of cutaneous T-cell lymphoma. It is a selective agonist of retinoid $X$ receptor (RXR), a member of the nuclear receptor superfamily. RXR functions by forming heterodimer with thyroid hormone receptor and other nuclear receptors. T3 exerts a negative feedback effect on the transcription of the $\beta$-subunit of TSH after binding to its receptor and subsequent heterodimerisation with RXR.

\section{Mechanism of thyroid dysfunction}

Bexarotene alters the feedback effect of thyroid hormone on the pituitary by causing reversible thyroid hormone-independent inhibition of TSH gene expression. It blocks transcription even in the absence of T3, and decreases TSH production. ${ }^{82,83}$ Besides, bexarotene causes direct inhibition of TSH secretion, and a rapid fall in serum TSH occurs even after the administration of a single dose..$^{84}$

\section{Central hypothyroidism}

Oral bexarotene administration has been found to induce rapid onset and reversible central hypothyroidism. ${ }^{82}$ In trials with more than 20 patients on bexarotene, the percentage of patients developing central hypothyroidism varied from 29-100\%. ${ }^{82,85-92}$ In a recently published study from Japan, hypothyroidism developed at 1 week in 45/66 patients, and only five patients remained euthyroid at 1 month..$^{22}$ Serum TSH levels returned to normal within 1 week of discontinuation of bexarotene in $90 \%$ of cases who were euthyroid earlier. ${ }^{82}$ 
The factors predicting the development of central hypothyroidism are higher doses of bexarotene $\left(>300 \mathrm{mg} / \mathrm{m}^{2} /\right.$ day) and prior treatment with IFN- $\alpha .{ }^{82}$ The aforementioned Japanese study also demonstrated that a pre-treatment FT4 (free thyroxine) value in the lower-normal range or a pre-treatment TSH value $<1.30 \mathrm{mIU} / \mathrm{L}$ correlated with the development of central hypothyroidism. Iodine deficiency and polymorphism of the $R X R \gamma 1$ gene were also proposed as other possible determinants of the development of central hypothyroidism. ${ }^{22} \mathrm{RXR} \gamma$ and the negative thyroid hormone-responsive element are both present in the promoter region of the gene encoding the TSH- $\beta$ subunit, and bind to retinoid and thyroid receptors respectively to inhibit its transcription. ${ }^{93}$

\section{Other effects on thyroid metabolism}

Bexarotene also exerts peripheral effects by increasing the degradation of thyroid hormones. Ten post-thyroidectomy patients with pulmonary metastases of differentiated thyroid carcinoma who received a 6-week redifferentiation course of bexarotene had a drastic fall in serum total T4, FT4 and total T3 levels. The increased catabolism of thyroid hormone was thought to be independent of peripheral deiodinase activity and likely to be mediated by other pathways like glucuronidation and sulphation. ${ }^{94}$

\section{Management}

The recommendations suggest initiation of LT4 at 25-50 $\mu \mathrm{g}$ per day when bexarotene treatment is started..$^{95-7}$ FT4 levels should be monitored every 1-2 weeks for first 4 weeks and adjusted to maintain FT4 within the upper third of the local laboratory normal range. There is no role of monitoring serum TSH levels. Once two consecutive blood reports are stable, frequency of monitoring can be decreased to once every 4 weeks. LT4 should be discontinued on stopping bexarotene unless the individuals have pre-existing primary hypothyroidism. Those with pre-existing primary hypothyroidism will have an increased LT4 requirement, as bexarotene increases the peripheral degradation of thyroid hormones. The dose of LT4 should be adjusted according to T4 levels and the dose requirement can increase two to three times. On stopping bexarotene, the dose of LT4 should be reduced to pre-treatment dose. Maintaining normal thyroid function has a beneficial effect on clearance of lipids and will help in the management of hypertriglyceridaemia, another known complication of bexarotene.

\section{Conclusion}

Immune-based and targeted chemotherapy agents can produce a distinct group of immune-related adverse events, foremost among them being thyroid dysfunction. Appropriate screening for primary thyroid dysfunction should be performed when immune checkpoint inhibitors, $\mathrm{TKI}$, IFN- $\alpha, I L-2$, thalidomide and other immunomodulatory drugs are administered. Guidelines and recommendations on the management of thyroid disorders induced by common anticancer drugs are summarised in Table $2 .{ }^{12,13,37,79,93-5}$ Central hypothyroidism is also described as a common adverse event with bexarotene and immune checkpoint inhibitors, albeit through different mechanisms. Administration of LT4 should be instituted when appropriate. In many cases, the thyroid dysfunction is temporary and treatment can be withdrawn with discontinuation of anticancer therapy.
1. Hamnvik $O P$, Larsen $P R$, Marqusee $E$. Thyroid dysfunction from antineoplastic agents. J Natl Cancer Inst. 2011;103:1572-87.

2. Sasidharan Nair V, Elkord E. Immune checkpoint inhibitors in cancer therapy: a focus on T-regulatory cells. Immunol Cell Biol. 2018;96:21-33.

3. Seidel JA, Otsuka A, Kabashima K. Anti-PD-1 and anti-CTLA-4 therapies in cancer: mechanisms of action, efficacy, and limitations. Front Oncol. 2018:8:86.

4. Ferrari SM, Fallahi P, Galetta F, et al. Thyroid disorders induced by checkpoint inhibitors. Rev Endocr Metab Disord. 2018;19:325-33

5. Corsello SM, Barnabei A, Marchetti P, et al. Endocrine side effects induced by immune checkpoint inhibitors. I Clin Endocrinol Metab. 2013;98:1361-75.

6. Faje AT, Sullivan R, Lawrence D, et al. Ipilimumab-induced hypophysitis: a detailed longitudinal analysis in a large cohort of patients with metastatic melanoma. J Clin Endocrinol Metab. 2014;99:4078-85.

7. Ryder M, Callahan M, Postow MA, et al. Endocrine-related adverse events following ipilimumab in patients with advanced melanoma: a comprehensive retrospective review from a single institution Endocr Relat Cancer. 2014:21:371-81.

single institution. Endocr Relat Cancer. 2014,21.371-8 ophthalmopathy related to melanoma biological therapy. Eur J ophthalmopathy related to $\mathrm{me}$

9. Borodic G, Hinkle DM, Cia Y. Drug-induced Graves disease from CTLA-4 receptor suppression. Ophthal Plast Reconstr Surg. 2011;27:e87-8.

10. Gan EH, Mitchell AL, Plummer R, et al. Tremelimumab-induced graves hyperthyroidism. Eur Thyroid J. 2017;6:167-70.

11. Osorio JC, Ni A, Chaft JE, et al. Antibody-mediated thyroid dysfunction during T-cell checkpoint blockade in patients with non-small-cell lung cancer. Ann Oncol. 2017;28:583-9.

12. Puzanov I, Diab A, Abdallah $\mathrm{K}$, et al. Managing toxicities associated with immune check-point inhibitors: consensus recommendations from the Society for Immunotherapy of Cancer (SITC) toxicity management working group. J Immunother Cancer. 2017:5:95

13. Brahmer JR, Lacchetti C, Schneider BJ, et al. Management of immune-related adverse events in patients treated with immune checkpoint inhibitor therapy: American Society of Clinical Oncology clinical practice guideline. J Clin Oncol. 2018;36:1714-68.

14. Byun DJ, Wolchok JD, Rosenberg LM, Girotra M. Cancer immunotherapy-immune checkpoint blockade and associated endocrinopathies. Nat Rev Endocrinol. 2017;134:195-207.

15. Girotra M, Hansen A, Farooki A, et al. The current understanding of the endocrine effects from immune checkpoint inhibitors and recommendations for management. J $\mathrm{NCl}$ Cancer Spectr. 2018;2:pky021.

16. Le Tourneau C, Faivre S, Raymond E. New developments in multitargeted therapy for patients with solid tumours. Cancer Treat Rev. 2008:34:3-48.

17. Jiao $Q, B i$, Ren $Y$, et al. Advances in studies of tyrosine kinase inhibitors and their acquired resistance. Mol Cancer. 2018;17:36.
18. Miyake H, Kurahashi T, Yamanaka K, et al. Abnormalities of thyroid function in Japanese patients with metastatic renal cell carcinoma treated with sorafenib: a prospective evaluation. Urol Oncol. 2010:28:515-9.

19. de Groot JW, Zonnenberg BA, Plukker JT, et al. Imatinib induces hypothyroidism in patients receiving levothyroxine. Clin Pharmacol Ther. 2005:78:433-8.

20. Ahmadieh $\mathrm{H}$ Salti I Tyrosine kinase inhibitors induced thyroid dysfunction: a review of its incidence, pathophysiology, clinical relevance, and treatment. Biomed Res int. 2013;2013:725410

21. Kollmannsberger C, Soulieres D, Wong R, et al. Sunitinib therapy for metastatic renal cell carcinoma: recommendations for management of side effects. Can Urol Assoc J. 2007;1(Suppl. 2):S41-54.

22. Rini BI, Tarnaskar I, Shaheen P, et al. Hypothyroidism in patients with metastatic renal cell carcinoma treated with sunitinib. J Natl Cancer Inst. 2007;99:81-3.

23. Akaza $\mathrm{H}$, Naito $\mathrm{S}$, Ueno $\mathrm{N}$, et al. Real-world use of sunitinib in Japanese patients with advanced renal cell carcinoma: efficacy safety and biomarker analyses in 1689 consecutive patients. safety and biomarker analyses in
Jpn I Clin Oncol. 2015:45:576-83.

24. Funakoshi T, Shimada Y Risk of hypothyroidism in patients with cancer treated with sunitinib: a systematic review and meta-analysis. Acta Oncol. 2012;52:691-702.

25. Wolter $P$, Stefan $C$, Decallonne B, et al. The clinical implications of sunitinib-induced hypothyroidism: a prospective evaluation Br J Cancer. 2008;99:448-54.

26. Desai J, Yassa L, Marqusee E, et al. Hypothyroidism after sunitinib treatment for patients with gastrointestinal stromal tumors. Ann Intern Med. 2006;145:660-4.

27. Clemons J, Gao D, Naam M, et al. Thyroid dysfunction in patients treated with sunitinib or sorafenib. Clin Genitourin Cancer. 2012;10:225-31.

28. Feldt $S$, Schüssel $K$, Quinzler $R$, et al. Incidence of thyroid hormone therapy in patients treated with sunitinib or sorafenib: a cohort study. Eur J Cancer. 2012;48:974-81.

29. Tamaskar I, Bukowski R, Elson P, et al. Thyroid function test abnormalities in patients with metastatic renal cell carcinoma treated with sorafenib. Ann Oncol. 2008;19:265-8.

30. Hutson TE, Lesovoy V, Al-Shukri S, et al. Axitinib versus sorafenib as first-line therapy in patients with metastatic renal-cell carcinoma: a randomised open-label phase 3 trial. Lancet Oncol. 2013;14:1287-94.

31. Sternberg CN, Davis ID, Mardiak J, et al. Pazopanib in locally advanced or metastatic renal cell carcinoma: results of a randomized phase III trial. J Clin Oncol. 2010:28:1061-8.

32. Makita N, liri T. Tyrosine kinase inhibitor-induced thyroid disorders: a review and hypothesis. Thyroid. 2013;23:151-9.

33. Ramsden JD. Angiogenesis in the thyroid gland. J Endocrinol. 2000:166:475-80.

34. Makita N, Miyakawa M, Fujita T, liri T. Sunitinib induces hypothyroidism with a markedly reduced vascularity. Thyroid. 2010:20:323-6

35. Lechner MG, Vyas $\mathrm{CM}$, Hamnvik OR, et al. Risk factors for new hypothyroidism during tyrosine kinase inhibitor therapy in advanced nonthyroidal cancer patients. Thyroid. 2018;28:437-44

36. Abdulrahman RM, Verloop $\mathrm{H}$, Hoftizer $\mathrm{H}$, et al. Sorafenib-induced hypothyroidism is associated with increased type 3 deiodination. J Clin Endocrinol Metab. 2010;95:3758-62

37. Sherman SI, Wirth $\mathrm{L}$, Droz JP, et al. Motesanib diphosphate in progressive differentiated thyroid cancer. N Eng/ I Med. 2008;359:31-4.

38. Braun $D$, Kim TD, le Coutre $P$, et al. Tyrosine kinase inhibitors noncompetitively inhibit MCT8-mediated iodothyronine transport. J Clin Endocrinol Metab. 2012;97:E100-5.

39. Drui D, Illouz F, Do Cao C, Caron P. Expert opinion on thyroid complications of new anti-cancer therapies: tyrosine kinase inhibitors. Ann Endocrinol (Paris). 2018;79:569-73.

40. Jonasch $\mathrm{E}$, Haluska FG. Interferon in oncological practice: review of interferon biology, clinical applications, and toxicities. Oncologist. 2001;6:34-55.

41. Corssmit EP, de Metz J, Sauerwein HP, Romijn JA. Biologic responses to IFN-alpha administration in humans. J Interferon Cytokine Res. 2000:20:1039-47.

42. Yue SJ, Enomoto T, Matsumoto Y et al. Thyrocyte class I and class II upregulation is a secondary phenomenon and does not contribute to the pathogenesis of autoimmune thyroid disease. Thyroid. 1998;8:755-63.

43. Marazuela M, Garcia-Buey L, Gonzalez-Fernandez B, et al. Thyroid autoimmune disorders in patients with chronic hepatitis $\mathrm{C}$ before and during interferon-alpha therapy. Clin Endocrinol (OXf). 1996;44:635-42.

44. Mandac JC, Chaudhry S, Sherman KE, Tomer Y. The clinical and physiological spectrum of interferon-alpha induced thyroiditis: toward a new classification. Hepatology. 2006;43:661-72.

45. Obołończyk L, Siekierska-Hellmann M, Sworczak K. Side effects during interferon-alpha therapy of hepatitis $\mathrm{C}$ with special consideration of thyroid dysfunction. Postepy Hig Med Dosw consideration of thyroid dysf

46. Torino F, Barnabei A, Paragliola R, et al. Thyroid dysfunction as an unintended side effect of anticancer drugs. Thyroid. 2013;23:1345-66.

47. Tomer Y, Blackard JT, Akeno N. Interferon alpha treatment and thyroid dysfunction. Endocrinol Metab Clin North Am. 2007;36:1051-66

48. Chalan P, Di Dalmazi G, Pani F, et al. Thyroid dysfunctions secondary to cancer immunotherapy. I Endocrinol Invest. 2018;41:625-38

49. Fehniger TA, Cooper MA, Caligiuri MA. Interleukin-2 and interleukin-15: immunotherapy for cancer. Cytokine Growth Factor Rev. 2002;13:169-83.

50. Krouse RS, Royal RE, Heywood G, et al. Thyroid dysfunction in 281 patients with metastatic melanoma or renal carcinoma treated with interleukin-2 alone. I Immunother Emphasis Tumor Immunol. 1995;18:272-8.

51. Curti B, Daniels GA, MCDermott DF, et al. Improved surviva and tumor control with Interleukin-2 is associated with 
the development of immune-related adverse events: data from the PROCLAIM ${ }^{\mathrm{MM}}$ registry. J Immunother Cancer. 2017;5:102.

52. Weijl $\mathrm{NI}$, Van der Harst $\mathrm{D}$, Brand $\mathrm{A}$, et al. Hypothyroidism during immunotherapy with interleukin-2 is associated with during immunotherapy with interleukin- 2 is associated with
antithyroid antibodies and response to treatment. J Clin Oncol. 1993;11:1376-83.

53. Atkins MB, Mier JW, Parkinson DR, et al. Hypothyroidism afte treatment with interleukin-2 and lymphokine-activated killer cells. N Eng/ J Med. 1988;318:1557-63.

54. Mier JW, Vachino G, van der Meer JW, et al. Induction of circulating tumor necrosis factor (TNF alpha) as the mechanism for the febrile response to interleukin-2 (IL-2) in cancer patients. J Clin Immunol. 1988;8:426-36.

55. Lotze MT, Matory YL, Ettinghausen SE, et al. In vivo administration of purified human interleukin 2. II. Half life, immunologic effects, and expansion of peripheral lymphoid cells in vivo with recombinant 112 . I mmuno 1985;135:2865-75.

56. Hill-Cawthorne GA, Button T, Tuohy O, et al. Long term lymphocyte reconstitution after alemtuzumab treatment of multiple sclerosis. J Neurol Neurosurg Psychiatry. 2012;83:298-304.

57. Pariani N, Willis M, Muller I, et al. Alemtuzumab-induced thyroid dysfunction exhibits distinctive clinical and immunologica features. J Clin Endocrinol Metab. 2018;103:3010-8.

58. Daniels GH, Vladic A, Brinar V, et al. Alemtuzumab-related thyroid dysfunction in a phase 2 trial of patients with relapsing-remitting multiple sclerosis. $J$ Clin Endocrinol Metab. 2014;99:80-9.

59. Pflug N, Cramer P, Robrecht S, et al. New lessons learned in T-PLL: results from a prospective phase-II trial with fludarabine-mitoxantrone-cyclophosphamide-alemtuzumab induction followed by alemtuzumab maintenance. Leuk Lymphoma. 2019;60:649-57.

60. Fiegl M Stauder $\mathrm{R}$ Steurer $\mathrm{M}$, et al Alemtuzumab in chronic lymphocytic leukemia: final results of a large observational multicenter study in mostly pretreated patients. Ann Hematol. 2014;93:267-77.

61. Jones JL, Thompson SA, Loh P, et al. Human autoimmunity after lymphocytte depletion is caused by homeostatic T-cell proliferation. Proc Natl Acad Sci USA 2013;110:20200-5

62. Zhu YX, Kortuem KM, Stewart AK. Molecular mechanism of action of immune-modulatory drugs thalidomide, Ienalidomide and pomalidomide in multiple myeloma. Leuk Lymphoma. 2013;54:683-7.

63. Badros AZ, Siegel E, Bodenner D, et al. Hypothyroidism in patients with multiple myeloma following treatment with thalidomide. Am J Med. 2002;112:412-3.

64. Figaro MK, Clayton $\mathrm{W} \mathrm{Jr}$, Usoh C, et al. Thyroid abnormalities in patients treated with lenalidomide for hematological in patients treated with lenalidomide for hematological
malignancies: results of a retrospective case review. Am J malignancies: results of a
Hematol 2011:86:467-70.

65. lams WT, Hames ML, Tsai JP, et al. Increased serum tumor necrosis factor $\alpha$ levels in patients with lenalidomide-induced hypothyroidism. Exp Hematol. 2015;43:74-8.
66. Hamadeh IS, Bourdage KL, Davis AC, Moreb JS. Pomalidomide induced hypothyroidism in a multiple myeloma patient: a case report. Ann Hematol Oncol. 2015:2:1057.

67. Ali SH, Aljenaee $\mathrm{K}$, Wan Mahmood WA, Hatunic M. Pomalidomide-induced hypothyroidism. Endocrinol Diabetes Metab Case Rep 2017:2017:pii:17-0110.

68. Slean GR, Silkiss RZ. Lenalidomide-associated thyroid-related eyelid retraction. Ophthalmic Plast Reconst Surg. 2018;34:e46-8.

69. Wasim AS, Shimon H, Margaret LB, Shichun B. Recurrent painless thyroiditis with sequential thyrotoxicosis and hypothyroidism after 2 courses of Ienalidomide. AACE Clinical Case Reports. 2016;2:e228-32.

70. LeBlanc R, Hideshima T, Catley LP, et al. Immunomodulatory drug costimulates T cells via the B7-CD28 pathway. Blood. 2004;103:1787-90

71. Bae J, Keskin DB, Cowens, K, et al. Lenalidomide polarizes Th1-specific anti-tumor immune response and expands XBP1 antigen-specific central memory $C D 3^{+} C D 8^{+} T$ cells against

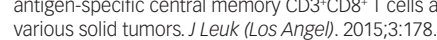

72. Giagounidis A, Fenaux P Mufti GJ, et al. Practical recommendations on the use of lenalidomide in the management of myelodysplastic syndromes. Ann Hematol. management of my

73. Sharp SE, Trout AT, Weiss BD, Gelfand MJ. MIBG in neuroblastoma diagnostic imaging and therapy. Radiographics. 2016;36:258-78.

74. Kayano D, Kinuya S. Current consensus on I-131 MIBG therapy. Nucl Med Mol Imaging. 2018;52:254-65

75. Quach A, Ji L, Mishra V, et al. Thyroid and hepatic function after high-dose 131 I-metaiodobenzylguanidine (131 I-MIBG) therapy for neuroblastoma. Pediatr Blood Cancer. 2011;56:191-201.

76. van Santen $\mathrm{HM}$, Tytgat $\mathrm{GA}$, van de Wetering MD, et al. Differentiated thyroid carcinoma after 131 I-MIBG treatment for neuroblastoma during childhood: description of the first two cases. Thyroid. 2012;22:643-6.

77. van Santen HM de Kraker I, van Eck BL, et al. High incidence of thyroid dysfunction despite prophylaxis with potassium iodide during (131)--meta-iodobenzylguanidine treatment in children with neuroblastoma. Cancer. 2002;94:2081-9.

78. van Santen HM, de Kraker J, Vulsma T. Endocrine late effects from multi-modality treatment of neuroblastoma. Eur $\mathrm{I}$ Cancer 2005:41:1767-74

79. Picco P, Garaventa A, Claudiani F, et al. Primary hypothyroidism as a consequence of 131---metaiodobenzylguanidine treatment for children with neuroblastoma. Cancer. 1995;76:1662-4.

80. van Santen $\mathrm{H}$, Kraker J, van Eck B, et al. Improved radiation protection of the thyroid gland with thyroxine, methimazole, and potassium iodide during diagnostic and therapeutic use and potassium iodide during diagnostic and therapeutic use
of radiolabeled metaiodobenzylguanidine in children with of radiolabeled metaiodobenzylguanidine in
neuroblastoma. Cancer. 2003:98:389-96.

81. Waguespack SG. Thyroid sequelae of pediatric cancer therapy. Horm Res Paediatr. 2019;91:104-17.

82. Sherman SI, Gopal J, Haugen BR, et al. Central hypothyroidism associated with retinoid $\mathrm{X}$ receptor-selective ligands. N Eng J Med. 1999;340:1075-9.
83. Sharma V, Hays WR, Wood WM, et al. Effects of rexinoids on thyrotrope function and the hypothalamic-pituitary-thyroid axis. Endocrinology. 2006:147:1438-51.

84. Golden WM, Weber KB, Hernandez TL, et al. Single-dose rexinoid rapidly and specifically suppresses serum thyrotropin in normal subjects. I Clin Endocrinol Metab. 2007;92:124-30

85. Duvic M, Martin AG, Kim Y, et al. Phase 2 and 3 clinical trial of oral bexarotene (targretin capsules) for the treatment of refractory or persistent early-stage cutaneous T-cell lymphoma. Arch Dermatol. 2001;137:581-93.

86. Duvic $M$, Hymes $K$, Heald $P$, et al. Bexarotene is effective and safe for treatment of refractory advanced-stage cutaneous T-cell Iymphoma: multinational phase II-III trial results. I Clin Oncol. 2001;19:2456-71

87. Talpur R, Ward $\mathrm{S}, \mathrm{Apisarnthanarax} \mathrm{N}$, et al. Optimizing bexarotene therapy for cutaneous T-cell lymphoma. J Am Acad Dermatol. 2002;47:672-84.

88. Abbott RA, Whittaker SJ, Morris SL, et al. Bexarotene therapy for mycosis fungoides and Sézary syndrome. Br I Dermatol. 2009;160:1299-307.

89. Vakeva L, Ranki A, Hahtola S. Ten-year experience of bexarotene therapy for cutaneous T-cell lymphoma in Finland. Acta Derm Venereol. 2012;92:258-63.

90. Quereux G, Saint-Jean M, Peuvrel L, et al. Bexarotene in cutaneous T-cell lymphoma: third retrospective study of long-term cohort and review of the literature. Expert Opin Pharmacother. 2013;14:1711-21.

91. Sokolowska-Wojdylo M, Florek A, Zaucha JM, et al. Polish lymphoma research group experience with bexarotene in the treatment of cutaneous T-cell lymphoma. Am J Ther. 2016;23:e749-56

92. Makita N, Manaka K, Sato J, et al. Bexarotene-induced hypothyroidism: characteristics and therapeutic strategies Clin Endocrinol (Oxf). 2019; 91:195-200.

93. Haugen BR, Brown NS, Wood WM et al. The thyrotrope-restricted isoform of the retinoid- $X$ receptor-gamma1 mediates 9 -cis-retinoic acid suppression of thyrotropin-beta promoter activity. Mol Endocrinol. 1997;11:481-9.

94. Smit JW, Stokkel MP, Pereira AM, et al. Bexarotene-induced hypothyroidism: bexarotene stimulates the peripheral metabolism of thyroid hormones. I Clin Endocrinol Metab. 2007:92:2496-9.

95. Sherman SI. Etiology, diagnosis, and treatment recommendations for central hypothyroidism associated with bexarotene therapy for cutaneous T-cell lymphoma. Clin Lymphoma. 2003;3:249-52.

96. Assaf C, Bagot M, Dummer R, et al. Minimizing adverse side-effects of oral bexarotene in cutaneous T-cell lymphoma: an expert opinion. $\mathrm{Br}$ I Dermatol. 2006;155:261-6.

97. Scarisbrick $\Perp$ Morris S, Azurdia R, et al. U.K. consensus statement on safe clinical prescribing of bexarotene for patients with cutaneous T-cell lymphoma. Br J Dermato 2013;168:192-200 